\title{
Prevalence of Cardiovascular Risk Factors and Heterozygous Familial Hypercholesterolemia in Premature Atherosclerotic Patients Presenting with Acute Coronary Syndrome
}

\author{
Ahmed Ashraf Reda, Mahmoud Ali Soliman, Ahmed Mokhtar Elkersh, Sabry Rasmy Yousef \\ Department of Cardiology, Menoufia University, Menoufia, Egypt \\ Email: Dr.sabry.yousef@gmail.com
}

How to cite this paper: Reda, A.A., Soliman, M.A., Elkersh, A.M. and Yousef, S.R. (2021) Prevalence of Cardiovascular Risk Factors and Heterozygous Familial Hypercholesterolemia in Premature Atherosclerotic Patients Presenting with Acute Coronary Syndrome. World Journal of Cardiovascular Diseases, 11, 195-209.

https://doi.org/10.4236/wjcd.2021.113020

Received: December 12, 2020

Accepted: March 20, 2021

Published: March 23, 2021

Copyright $\odot 2021$ by author(s) and Scientific Research Publishing Inc. This work is licensed under the Creative Commons Attribution International License (CC BY 4.0).

http://creativecommons.org/licenses/by/4.0/

\begin{abstract}
Background: Heterozygous familial hypercholesterolemia is an autosomal dominant genetic disorder with an estimated prevalence of 1/200 - 1/500 in the general population. Early identification of patient with familial hypercholesterolemia is important, because appropriate treatment may reduce the risk of premature atherosclerosis. Objective: Assessment of the prevalence of different modifiable cardiovascular risk factors and clinical diagnosis of heterozygous familial hypercholesterolemia. Methods: One hundred patients were enrolled, included young patients (males less than 50 years and females less than 60 years old) presented with first attack of acute coronary syndrome either ST elevation myocardial infarction (STEMI), non ST elevation myocardial infarction (NSTEMI) or unstable angina (UA). All patients were subjected to full history taking, general and local examination, Electrocardiogram, transthoracic Echocardiography, laboratory investigations, coronary angiography and Dutch score calculation for familial hyperlipidemias. Results: The mean level of serum cholesterol among studied group was $268.31 \pm$ 59.33, HDL-C was $39.63 \pm 7.52$, LDL was $192.27 \pm 60.61$ and TG was $180.10 \pm$ 39.64. With application of Dutch score, $20 \%$ of patients diagnosed definite familial hypercholesterolemia with Dutch score $>8$. Twenty-six percent of patients diagnosed as probable familial hypercholesterolemia with Dutch score 6 - 8. Thirty-nine percent patients diagnosed as possible familial hypercholesterolemia with Dutch score 3 - 5 and 15\% of patients were unlikely familial hypercholesterolemia with Dutch score $<3$ with significant correlation between Dutch score and age, total cholesterol, LDL-C, serum creatinine. Conclusion: Familial hypercholesterolemia (FH) is one of the most common serious genetic disorders of cholesterol metabolism. The early identification of
\end{abstract}


heterogynous $\mathrm{FH}$ patients is crucial to start an effective prevention strategy.

\section{Keywords}

Acute Coronary Syndrome, Heterozygous Familial

Hypercholesterolemia

\section{Introduction}

The increasing prevalence of CAD in aging and young populations is associated with modifiable risk factors, which include obesity and dyslipidemia as well as other contributing risk factors, which include age and sex [1].

Dyslipidemia is an established risk factor for CVD and increased serum low density lipoprotein-cholesterol (LDL-C) level is a major risk factor for CAD and thus the main target for its prevention. However, an acute exposure to high levels of serum LDL-C is not sufficient to determine the CAD onset. Indeed, prolonged exposure time to elevated levels of LDL-C is the main risk factor for acute coronary syndrome [2].

The etiology of FH comprises of known mutations in the gene of the LDL receptor (LDLR) (with more than 1600 identified to date, the proprotein convertase subtilisin/kexin type 9 (PCSK9) gene, the gene of Apo lipoprotein B (Apo B) or rare mutations in LDL receptor adapter protein 1 (LDLRAP1) gene [3].

Heterozygous familial hypercholesterolemia is an autosomal dominant genetic disorder with an estimated prevalence of 1/200 - 1/500 in the general population [4]. Early identification of patient with familial hypercholesterolemia is important, because appropriate treatment may reduce the risk of premature atherosclerosis [5].

We aimed to identify the prevalence of different modifiable cardiovascular risk factors and clinical diagnosis of heterozygous familial hypercholesterolemia.

\section{Material and Methods}

\subsection{Patient Population}

This is a retrospective cross-sectional study including a total of 100 patients admitted to Mahalla cardiac center. Patients were enrolled in the study after obtaining their written informed consent, and approval of the local ethics committee of the hospital.

Patients who included in the study were young patients (males less than 50 years and females less than 60 years old) presented with first attack of acute coronary syndrome either ST elevation myocardial infarction (STEMI), non ST elevation myocardial infarction (NSTEMI) or unstable angina (UA). They were admitted for primary PCI, thrombolytic therapy or full anti-ischemic treatment. these patients admitted during Saturday and Tuesday in Mahalla Cardiac Center emergency theatre. 


\subsection{Exclusion Criteria}

Patients with recurrent attack of acute coronary syndrome, patients already on statin therapy or anti-ischemic drugs and patients who underwent elective coronary revascularization were excluded from our study.

After exclusion of non-responders, drop out participants and those with exclusion criteria, 100 patients completed the study (this number was considered suitable enough sample for statistical analysis with significant results and correlations).

\subsection{Methods}

All patients were subjected to detailed history, including Including age, sex, history of CAD, medications and risk factors including hypertension, diabetes mellitus, smoking, dyslipidemia, history of previous TIA or stroke, vascular diseases and family history of premature ischemic heart disease and physical examination including local and general examination.

Electrocardiography (ECG) within 10 minutes' maximum from first medical contact to detect ST segment changes and T wave abnormalities for diagnosis of acute coronary syndrome

Laboratory investigations included, lipid profile as early as possible, complete blood picture, serum creatinine, TSH and cardiac biomarkers (CKMB and troponin). Some patients-who did not have history of CAD-performed a stress imaging test to diagnose CAD.

Echocardiographic images were obtained in the parasternal long-axis and shortaxis and apical two-chamber and four-chamber views using standard transducer positions. Phillips, General Electric Healthcare (GE Vingmed, Norway) equipped with a harmonic M5S variable-frequency $(1.7-4 \mathrm{MHz})$ phased-array transducer was used to detect wall motion abnormalities and assessment of LV systolic function, EDD, ESD, PWD, IVSD, FS and LVEF were measured and the results were done blindly by two echo experts for all subjects according to ASE recommendations.

The hundred patients underwent Coronary angiography (CA) with or without PCI during hospital stay by femoral approach in multiple views using Sildenger technique. CAs were analyzed by experienced angiographer who was blinded to clinical status of the patients. Right anterior oblique and left anterior oblique views were used for evaluation of the left and right coronary system, respectively.

Dutch score was calculated for all patients for the diagnosis of FH taking into consideration family history of hyperlipidemia or heart disease, clinical characteristics such as tendinous xanthomata, elevated LDL cholesterol, and/or an identified mutation. A total point score of greater than 8 is considered "definite" $\mathrm{FH}, 6-8$ is "probable" FH, and $3-5$ is "possible" FH. In comparison to the Simon Broome, the Dutch criteria requires that at least one other criterion be met in addition to molecular diagnosis. 


\subsection{Statistical Analysis}

Statistical analysis was performed using Statistical Package for The Social Sciences Version 22 (IBM Corp., Armonk, NY, USA). Quantitative data are expressed as means and standard deviations.

P-Value $\leq 0.05$ was considered to indicate significance. Correlation analysis assesses the strength of association between two variables.

\section{Results}

Regarding to age, the mean age of our patients was $47.09 \pm 6.25 \mathrm{y}$. There were 75 patients with age $<50 \mathrm{y}$ and 25 patients with age $\geq 50 \mathrm{y}$. Regarding to sex, $68 \%$ of patients were male while $32 \%$ were female, for marital status, $83 \%$ of patients were married and $17 \%$ of patients were single. Eight percent of patients were Illiterate/read and write, $25 \%$ of patients were Primary educated, $41 \%$ of patients were Secondary educated and $26 \%$ of patients were University educated (Table 1 ).

Patients were categorized according to risk factors they have. $61 \%$ of patients were hypertensive and $51 \%$ of patients were diabetics (6 patients with type1 DM and 45 patients with type $2 \mathrm{DM}$ ). $67 \%$ of patients were dyslipidemic, $61 \%$ of patients were current smokers and $58 \%$ of patients had positive family history (Table 2, Figure 1).

There were $2 \%$ of patients with past history of stroke/TIA. There were $4 \%$ of patients with CKD and 3\% of patients with peripheral vascular disease (Table 3).

Table 1. Demographic data and socio-economic status among the studied group.

\begin{tabular}{cc}
\hline Socio-demographic data & The studied group $(\mathbf{n}=100)$ \\
\hline Age/years & $47.09 \pm 6.25$ \\
$<50 \mathrm{y}$ & $75(75.0 \%)$ \\
$\geq 50 \mathrm{y}$ & $25(25.0 \%)$ \\
Sex & \\
Male & $68(68.0 \%)$ \\
Female & $32(32.0 \%)$ \\
Marital status & \\
Married & $83(83.0 \%)$ \\
Single & $17(17.0 \%)$ \\
level of Education & \\
Illiterate/read and write & \\
Primary educated & $25(8.0 \%)$ \\
Secondary educated & $25(25.0 \%)$ \\
University educated & $41.0 \%)$ \\
\end{tabular}


Table 2. Risk factors among the studied groups.

\begin{tabular}{cc}
\hline Risk factors & The studied group $(\mathbf{n}=100)$ \\
\hline HTN & $61(61.0 \%)$ \\
Type 1 DM & $6(6.0 \%)$ \\
Type 2 DM & $45(45.0 \%)$ \\
Dyslipidemia & $67(67.0 \%)$ \\
Smoking & $61(61.0 \%)$ \\
Family history & $58(58.0 \%)$ \\
\hline
\end{tabular}

Table 3. Previous non cardiac history among the studied group.

\begin{tabular}{cc}
\hline Previous non cardiac history & The studied group $(\mathbf{n}=100)$ \\
\hline Stroke/TIA & $2(2.0 \%)$ \\
Chronic kidney disease & $4(4.0 \%)$ \\
Peripheral vascular disease & $3(3.0 \%)$ \\
\hline
\end{tabular}

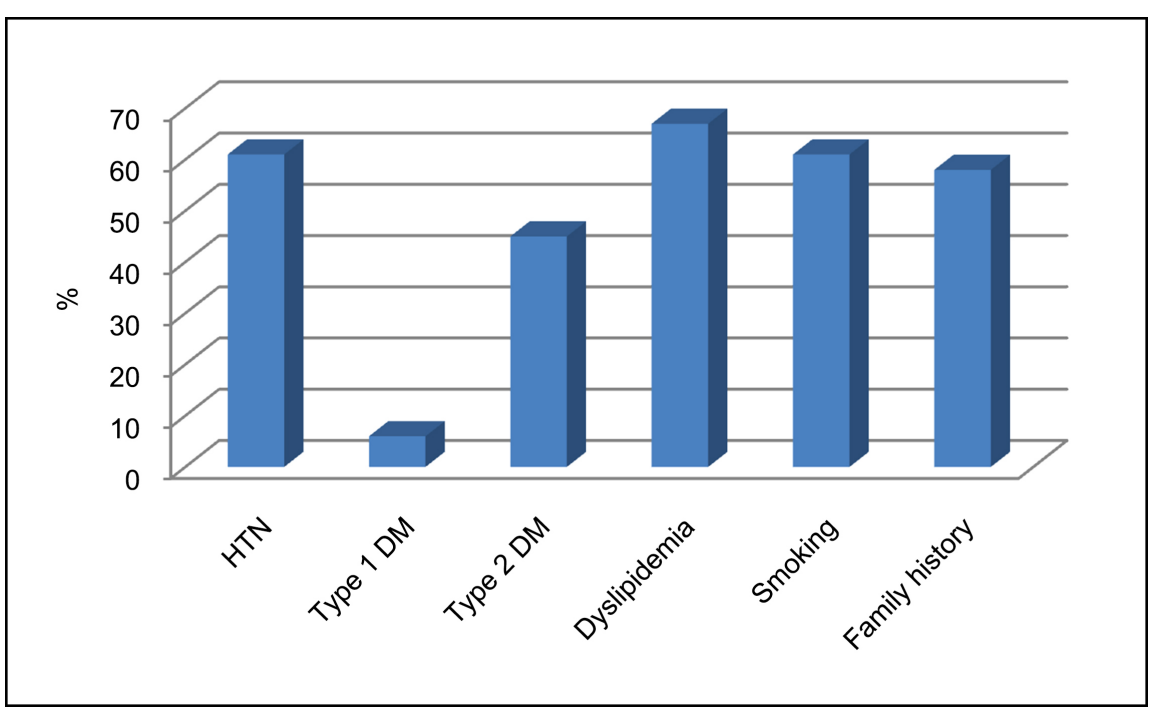

Figure 1. Risk factors among the studied group.

All patients had chest pain and dyspnea while 3 patients presented with cardiac arrest. 95\% of our patients presented with palpitation. Twenty-one percent of patients diagnosed as Non STEMI. $44 \%$ of patients presented with STEMI and $35 \%$ of patients presented with unstable angina (Table 4 ).

The mean body weight was $89.24 \pm 10.96 \mathrm{~kg}$. The mean height was $172.60 \pm$ 6.25 CM. The mean waist circumference was $105.30 \pm 15.68$ while the mean BMI was $30.31 \pm 3.81$. The mean SBP was $137.90 \pm 21.89$ while the mean HR was $94.12 \pm 14.97$. No patients with tendanous xanthomatosis while there were 3 patients had Arcus cornialis (Table 5). 
Table 4. First Symptoms and admission diagnosis among the studied group.

\begin{tabular}{cc}
\hline First Symptoms & The studied group $(\mathbf{n}=100)$ \\
\hline Chest pain & $100(100 \%)$ \\
Dyspnea & $100(100 \%)$ \\
Cardiac arrest & $3(3.0 \%)$ \\
Palpitation & $95(95.0 \%)$ \\
Admission diagnosis: & \\
Non STEMI & $21(21.0 \%)$ \\
STEMI & $44(44.0 \%)$ \\
Unstable angina & $35(35.0 \%)$ \\
\hline
\end{tabular}

Table 5. Physical examination on admission among the studied group.

\begin{tabular}{cc}
\hline Physical examination on admission & The studied group $(\mathbf{n}=100)$ \\
Weight & $89.24 \pm 10.96$ \\
Height & $172.60 \pm 6.25$ \\
Waist circumference & $105.30 \pm 15.68$ \\
BMI & $30.31 \pm 3.81$ \\
SBP & $137.90 \pm 21.89$ \\
HR & $94.12 \pm 14.97$ \\
Tendanous xanthomatosis & $0(0.0 \%)$ \\
Arcuscornialis & $3(3.0 \%)$ \\
\hline
\end{tabular}

The mean serum cholesterol was $268.31 \pm 59.33$, HDL-C was $39.63 \pm 7.52$ while LDL was $192.27 \pm 60.61$ and TG was $180.10 \pm 39.64$. The mean HB was $12.15 \pm 1.58$. The median for serum creatinine was 1.0. The median RBS was 141.50. The median CKMB was 83.00 while the median troponin was 5.10 and for TSH was 2.10 (Table 6).

With application of Dutch score on our patients, there were $20 \%$ of patients diagnosed Definite familial hypercholesterolemia with Dutch score $>8.265$ of patients diagnosed as Probable familial hypercholesterolemia with Dutch score 6 - 8. 39\% patients diagnosed as Possible familial hypercholesterolemia with Dutch score 3 - 5 and $15 \%$ of patients were Unlikely familial hypercholesterolemia with Dutch score $<3$ (Table 7, Figure 2).

All patients underwent coronary angiography $94 \%$ of them underwent PCI and 5\% underwent CABG. 9\% of patients receive thrombolytic therapy. All patients receive full medical treatment. $1 \%$ of our patients had pacemaker. The mean LVEF was $53.54 \pm 8.02 .1 \%$ had stress test (Table 8). 
Table 6. Laboratory investigations among the studied group.

\begin{tabular}{|c|c|}
\hline Laboratory investigations & The studied group $(n=100)$ \\
\hline $\begin{array}{c}\text { Total Cholesterol } \\
\text { Mean } \pm S D\end{array}$ & $268.31 \pm 59.33$ \\
\hline $\begin{array}{c}\text { HDL-c } \\
\text { Mean } \pm S D\end{array}$ & $39.63 \pm 7.52$ \\
\hline $\begin{array}{c}\text { LDL-c } \\
\text { Mean } \pm S D\end{array}$ & $192.27 \pm 60.61$ \\
\hline $\begin{array}{c}\text { TG } \\
\text { Mean } \pm S D\end{array}$ & $180.10 \pm 39.64$ \\
\hline $\begin{array}{c}\mathrm{Hb} \\
\text { Mean } \pm S D\end{array}$ & $12.15 \pm 1.58$ \\
\hline $\begin{array}{l}\text { Serum creatinine } \\
\text { Median (Min-Max) }\end{array}$ & $1.0(0.5-5.6)$ \\
\hline $\begin{array}{c}\text { RBS } \\
\text { Median (Min-Max })\end{array}$ & $141.50(74-500)$ \\
\hline $\begin{array}{c}\text { CKmb } \\
\text { Median }(\text { Min-Max })\end{array}$ & $83.00(23-168)$ \\
\hline $\begin{array}{c}\text { Treponin } \\
\text { Median (Min-Max) }\end{array}$ & $5.10(0.01-25)$ \\
\hline $\begin{array}{c}\text { TSH } \\
\text { Median }(\text { Min-Max })\end{array}$ & $2.10(0.8-6.4)$ \\
\hline
\end{tabular}

Table 7. Dutch score among the studied group.

\begin{tabular}{cc}
\hline Dutch score & The studied group $(\mathrm{n}=100)$ \\
\hline Median (Min-Max) & $3.0(0-8)$ \\
Diagnosis & \\
Definite familial hypercholesterolemia $>8$ & $20(20 \%)$ \\
Probable familial hypercholesterolemia $6-8$ & $26(26 \%)$ \\
Possible familial hypercholesterolemia $3-5$ & $39(39 \%$ \\
Unlikely familial hypercholesterolemia $<3$ & $15(15 \%)$ \\
\hline
\end{tabular}

Table 8. Clinical and radiological data.

\begin{tabular}{cc}
\hline Variables & The studied group $(\mathbf{n}=100)$ \\
\hline Medical treatment & $100(100 \%)$ \\
Coronary angiography & $100(100 \%)$ \\
PCI & $94(94 \%)$ \\
CABG & $5(5.0 \%)$ \\
Pacemaker & $1(1.0 \%)$ \\
Thrombolytic & $9(9.0 \%)$ \\
LV EF & $53.54 \pm 8.02$ \\
Stress test & $1(1.0 \%)$ \\
Radio test & $0(0 \%)$ \\
\hline
\end{tabular}


There was significant positive correlation between Dutch score and Total Cholesterol, LDL-C and serum creatinine with $\mathrm{p}$ value $\leq 0.001, \leq 0.001$ and 0.014 respectively and negative significant correlation with age with $\mathrm{p}$ value 0.021 . There was no correlation between Dutch score and other variables (Table 9, Figures 3-6).

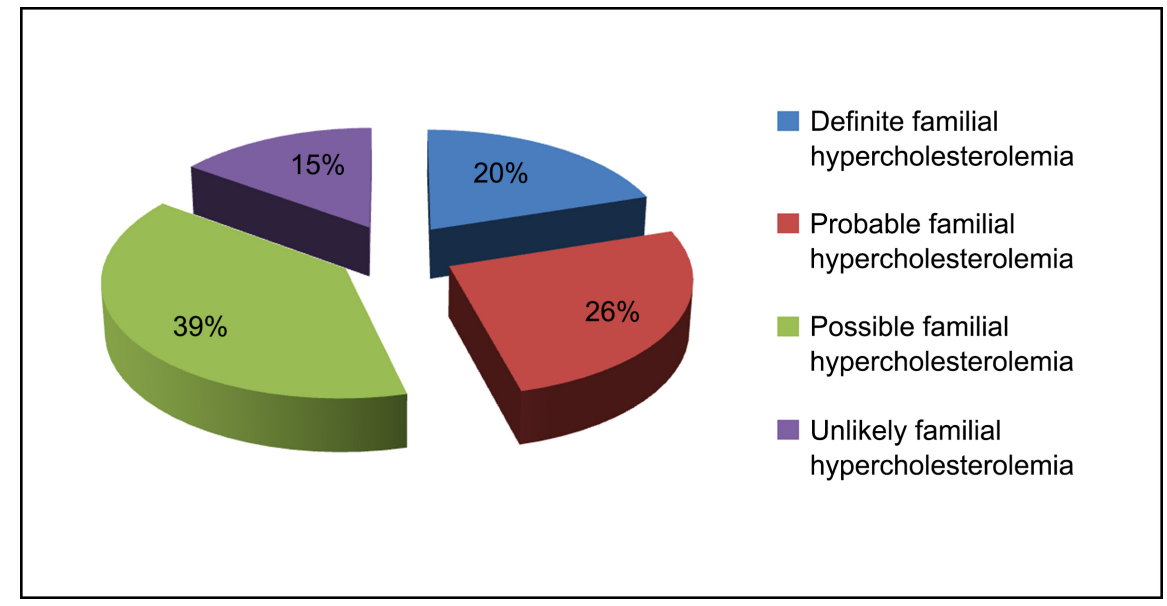

Figure 2. Diagnosis based on Dutch score among the studied group.

Table 9. Correlation between Dutch score and other variables.

\begin{tabular}{|c|c|c|}
\hline \multirow{2}{*}{ Variables } & \multicolumn{2}{|c|}{ Dutch score } \\
\hline & $\mathrm{r}$ & $\mathrm{p}$ \\
\hline Age/years & -0.231 & $0.021^{\star}$ \\
\hline Waist circumference & -0.120 & 0.236 \\
\hline BMI & -0.133 & 0.187 \\
\hline SBP & -0.005 & 0.957 \\
\hline HR & 0.046 & 0.651 \\
\hline LV EF & -0.090 & 0.376 \\
\hline Total Cholesterol & 0.918 & $\leq 0.001^{\star}$ \\
\hline HDL-c & -0.071 & 0.483 \\
\hline LDL-c & 0.912 & $\leq 0.001^{*}$ \\
\hline TG & 0.186 & 0.063 \\
\hline $\mathrm{Hb}$ & -0.142 & 0.159 \\
\hline S. Creatinine & 0.246 & $0.014^{*}$ \\
\hline RBS & 0.124 & 0.218 \\
\hline $\mathrm{CKmb}$ & -0.038 & 0.709 \\
\hline Treponin & -0.079 & 0.435 \\
\hline TSH & -0.138 & 0.171 \\
\hline
\end{tabular}

$\mathrm{r}$ : Spearman correlation, ${ }^{*}$ significant $p \leq 0.05$. 


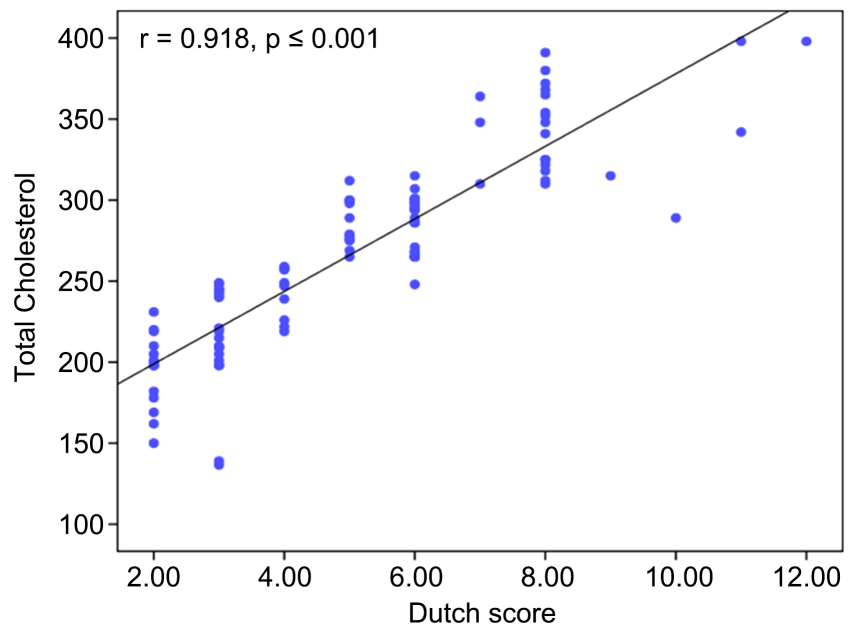

Figure 3. Scatter diagram for positive correlation between Dutch score and total Cholesterol.

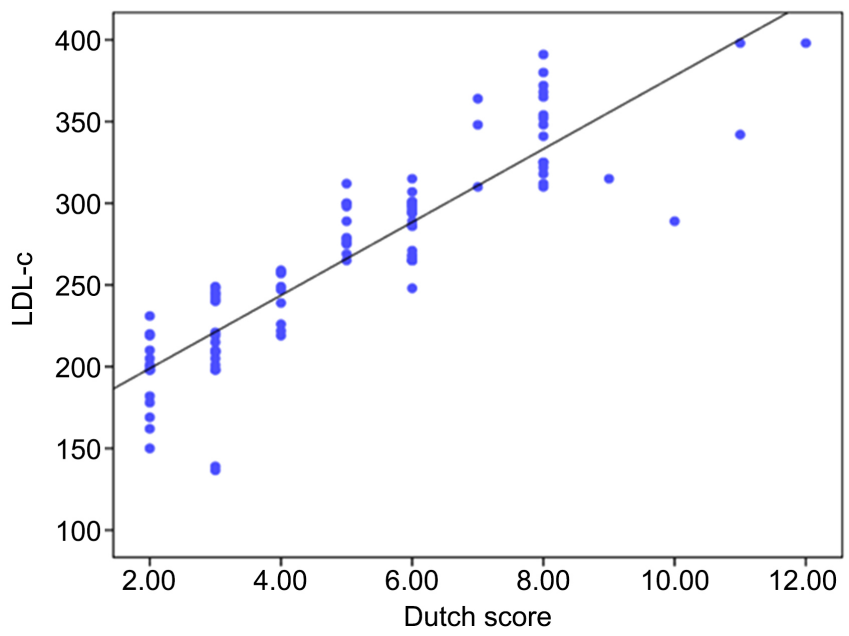

Figure 4. Scatter diagram for positive correlation between Dutch score and LDL level.

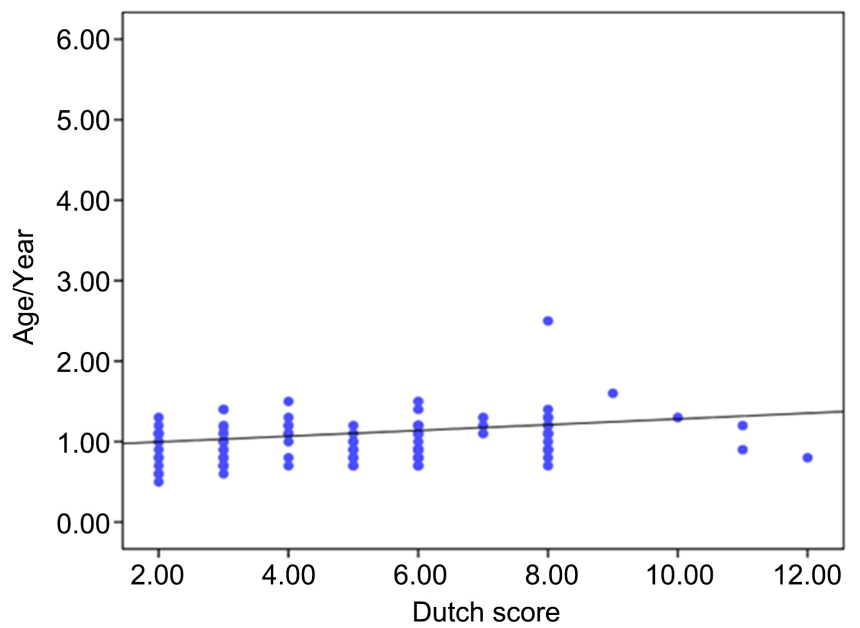

Figure 5. Scatter diagram for negative correlation between Dutch score and age of the patients. 


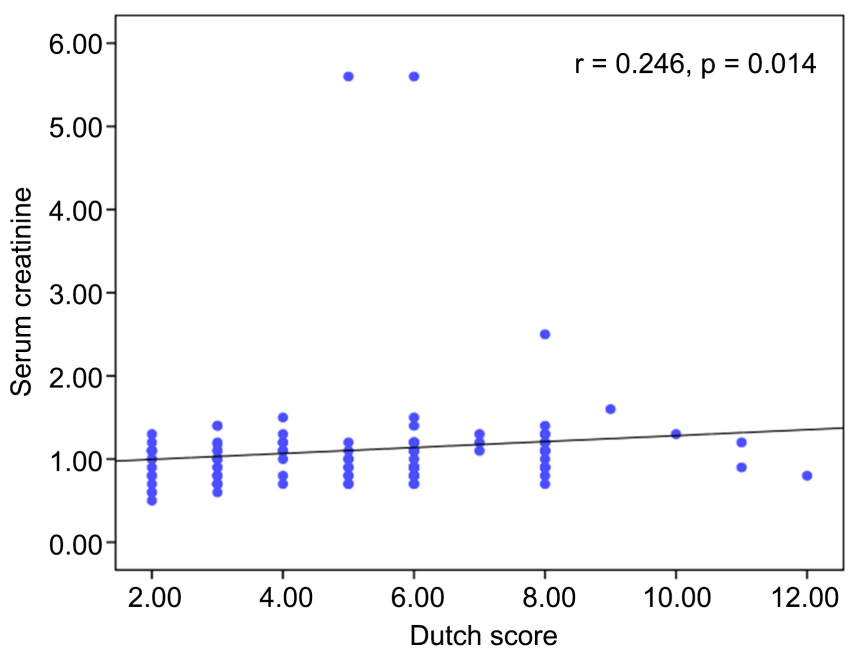

Figure 6. Scatter diagram for positive correlation between Dutch score and serum creatinine.

\section{Discussion}

Premature coronary artery disease is a major cause of mortality and morbidity. In 2002, a Danish study showed that the incidence of CAD among people between 30 and 54 of age was $1 \%$ for men and $0.4 \%$ for women per year [2].

$\mathrm{FH}$ is an autosomal co-dominant inherited disorder of lipoprotein metabolism characterized by high LDL-C plasma levels from birth and an increased risk of premature coronary heart disease. Mutations in the gene encoding the LDLR are the most commonly identified in these patients although mutations in APOB and PCSK9 have also been shown to result in FH [6].

We enrolled 100 consecutive young adult patients with premature (Male less than 50 years old and female less than 60 years old) acute coronary syndrome admitted to Mahalla Cardiac Center for primary PCI, thrombolytic, or full anti ischemic treatment.

Regarding to the age of the patients included in our study, the mean age of was $47.09 \pm 6.25$ years, there were 75 patients with age $<50 y$ and 25 patients with age $\geq 50 \mathrm{y}$. This was concordant with Shi et al., in which the mean age of patients presented with premature ACS was $52.7 \pm 7.6$ years [7].

Regarding to sex, the majority of our patients were males with a percentage of $68 \%$ patients while $32 \%$ patients were female. This was in concordant with our study, Sadeghi et al., stated that $73.6 \%$ of patients were males and $26.4 \%$ were females. Regarding to Marital status, 83 patients were married and 17 patients were single. Comparable with our study, Sadeghi et al., $90.4 \%$ of patients included in the study were married [8].

Regarding to risk factors in our study, $61 \%$ of our patients were hypertensive, $51 \%$ of patients had diabetes, $67 \%$ of our patients were dyslipidemic, $61 \%$ of patients were current smokers and $58 \%$ of patients had family history.

In contrast to our results, Mirza et al., showed that $26 \%$ of patients were hypertensive, $22 \%$ of patients were diabetic, $62 \%$ of patients were smokers and $24 \%$ of 
patients had family history of ACS. Also Iyengar et al., showed that $13 \%$ of patients had family history, $37 \%$ of patients were diabetic, $33 \%$ of patients were hypertensive, $50 \%$ of patients were dyslipidemia and $30 \%$ of patients were smokers [9] [10].

Our study showed that hypertension and dyslipidemia were common risk factors of premature acute coronary syndrome in our study. This was concordant with Harada-Shiba et al., in which HTN and dyslipidemia represented 73.4\% and $77.8 \%$ respectively [11].

Our study showed that $51 \%$ of our patients were diabetic, which was approved by Katsiki et al., who stated that diabetes mellitus is associated with increased prevalence of cardiovascular disease. Indeed, diabetic patients have a 2 - 4-fold higher risk for CVD morbidity and mortality than healthy non-diabetics [12].

Compared with individuals without diabetes, patients with diabetes mellitus have a considerably higher risk of cardiovascular morbidity and mortality, and are disproportionately affected by cardiovascular disease [13].

Smoking also is a common risk factor in our study with a percentage of $61.0 \%$. This may be due to high prevalence of smoking among Egyptian people which is concordant with Mirza et al., in which $62 \%$ of patients were smokers [9].

Our study showed that family history of premature CHD is a known risk factor for cardiovascular events. Evidence supports a higher incidence of subclinical atherosclerosis in the individuals with positive familial history of premature CHD [14].

As regarding to previous non cardiac history our study shows that there were $2 \%$ of patients with past history of stroke/TIA, $4 \%$ of patients with CKD and 3\% of patients with peripheral vascular disease.

In contrast to our study, Harada-Shiba et al., showed higher incidence of cerebrovascular events than our results with a percentage of $7.7 \%$ of patients while there were $1.9 \%$ of patients had peripheral vascular disease [15]. Another study Sadeghi et al., showed that $0.8 \%$ had renal insufficiency and no patients presented with stroke or PVD [8].

As regarding to admission diagnosis, $21 \%$ of our patients diagnosed as Non STEMI, $44 \%$ of patients presented with STEMI and $35 \%$ of patients presented with unstable angina. In Ralapanawa et al., about $7.7 \%$ of patients presented with unstable angina, $36.7 \%$ of patients presented with NSTEMI and $25.7 \%$ presented with STEMI [16].

Regarding to physical examinations, the mean weight was $89.24 \pm 10.96$ and the mean BMI was $30.31 \pm 3.81$. The mean height was $172.60 \pm 6.25$. The mean waist circumference was $105.30 \pm 15.68$. This was concordant with Mirza et al., in which BMI was 29 and waist circumference 98. In Lamelas et al., mean BMI was $27.3 \pm 4.7 \mathrm{~kg} / \mathrm{m}^{2}$ [9] [17].

The mean SBP was $137.90 \pm 21.89$. The mean HR was $94.12 \pm 14.97$. In contrast with our study, Ge et al., stated that the mean SBP in patients with ACS was $128.6 \pm 19.4$ and the mean HR was $72.0 \pm 14.4$, this may be due to small sample 
size of our study [18].

Xanthomas are commonly caused by a disturbance of lipoprotein metabolism. Tendon xanthomas are cholesterol deposits in tendons. They appear as slowly enlarging papules or subcutaneous nodules attached to tendons, ligaments, fascia and periosteum and commonly affect the tendons of the dorsal surface of the hands and the achilles tendon. Their presence is a clinical sign of familial hypercholesterolemia [19].

Arcus cornealis (corneal arcus) is a single corneal circle of lipid deposits parallel to the limbus that usually affects both eyes symmetrically. This greyish stromal ring appears in the superior and inferior corneal periphery and extends around it [20].

In our study, no patient had tendinous xanthomatosis while 3 patients had Arcus cornialis. In contrast to our study, Sawhney et al., stated that $8.35 \%$ had arcus cornialis and $0.16 \%$ of patients had tendinous xanthomatosis, this may be high main age in our study [21].

Regarding to laboratory investigations, the mean level of serum cholesterol was $268.31 \pm 59.33$. The mean level of HDL was $39.63 \pm 7.52$ while the mean level of LDL was $192.27 \pm 60.61$. The mean level of TG was $180.10 \pm 39.64$. The mean level of $\mathrm{HB}$ was $12.15 \pm 1.58$. The median level of serum creatinine was 1.0 (0.5 - 5.6).

In Sawhney et al., the total cholesterol level was $172.46 \pm 36.77$. The mean level of LDL was $135.10 \pm 43.43$ while the mean level of HDL was $33.26 \pm 6.88$. The mean TG level was $141.05 \pm 44.64$ [21].

In Cordero et al., the mean level of total cholesterol was 183.8. The mean level of LDL 114.2 while the mean level of HDL was 42.6. The mean TG level was 149.6. The median level of creatinine 0.9 while the mean level of HB 14.2 [22].

Dutch score is a criterion for the diagnosis of FH. Our results stated that $26 \%$ of patients diagnosed as Probable familial hypercholesterolemia with Dutch score $6-8$. Thirty-nine percent of the patients diagnosed as Possible familial hypercholesterolemia with Dutch score 3 - 5 and 15\% of patients were Unlikely familial hypercholesterolemia with Dutch score $<3$.

In contrast to our study, Auckle et al., stated that $3.8 \%$ of patients diagnosed as definite/probable $\mathrm{FH}, 42.4 \%$ diagnosed as possible $\mathrm{FH}$ while $53.8 \%$ of patients diagnosed as unlikely FH. Also in Farnier et al., there were $2.1 \%$ of patients diagnosed as definite/probable $\mathrm{FH}, 20.7 \%$ as possible and $77.2 \%$ diagnosed as unlikely FH [23] [24].

Regarding Correlation between Dutch score and other variables in our study there was a significant negative correlation between Dutch score and age $p=$ 0.021 , while there was a highly positive correlation with total cholesterol and LDL $p<0.001$.

This came in agreement with De Backer et al., who reported that patient with high Dutch score (definite/probable and possible $\mathrm{FH}$ ) were younger compared to patients not presenting $\mathrm{FH} p<0.0001$. In addition, those patients with definite 
FH also presented with higher levels of total cholesterol and LDL-C levels as compared to patients with possible FH and unlikely FH assessed by Dutch score at the time of enrolment; $P<0.0001$ [25].

Our results also were in agreement with Auckle et al., 363 men with FH identified using the Dutch Lipid Clinic Network Criteria were enrolled. Their baseline characteristics revealed that FH patients were younger ( 50.1 years vs. 53.5 years) had higher total cholesterol (7.38 \pm 0.934 vs. $10 \pm 1.02 \mathrm{mmol} / \mathrm{L} ; p<0.001)$ and LDL-C (5.77 \pm 0.362 vs. $69 \pm 0.41 \mathrm{mmol} / \mathrm{L} ; p<0.001)$ [23].

Our results showed significant positive correlation between Dutch score and creatinine level $p=0.014$ this was supported by Emanuelsson et al., who conducted a prospective cohort study of 106,172 individuals, of whom 7109 were diagnosed with FH by Dutch Lipid Clinic Network Criteria to assess the risk of PAD and CKD in patients with FH? The study showed that e GFR, was significantly lower in patient with definite $\mathrm{FH}$ than patients without FH; $p<0.001$ [26].

In contrast our results, De Backer et al., reported insignificant difference in creatinine levels among definite FH, possible FH and unlikely FH assessed by Dutch Lipid Clinic Network Criteria, this discrepancy may be due to small sample size of our own [25].

\section{Limitations}

The study lacked a large validation population and results obtained from only one center (Mahalla Cardiac Center). Further prospective studies are thus needed to confirm our results.

\section{Conclusion}

Familial hypercholesterolemia (FH) is one of the most common serious genetic disorders of cholesterol metabolism. The early identification of heterogynous FH patients is crucial to start an effective prevention strategy.

\section{Conflicts of Interest}

The authors declare no conflicts of interest regarding the publication of this paper.

\section{References}

[1] Davidson, L., Wilcox, J., Kim, D., et al. (2014) Clinical Features of Precocious Acute Coronary Syndrome. The American Journal of Medicine, 127, 140-144. https://doi.org/10.1016/j.amjmed.2013.09.025

[2] Pirazzi, C., Håkansson, L., Gustafsson, C., et al. (2019) High Prevalence of Genetic Determined Familial Hypercholesterolemia in Premature Coronary Artery Disease. The Application of Clinical Genetics, 12, 71-78. https://doi.org/10.2147/TACG.S202942

[3] Hopkins, P.N., Brinton, E.A. and Nanjee, M.N. (2014) Hyperlipoproteinemia Type 3: The Forgotten Phenotype. Current Atherosclerosis Reports, 16, 440. 
https://doi.org/10.1007/s11883-014-0440-2

[4] Cuchel, M., Bruckert, E., Ginsberg, H.N., et al. (2014) Homozygous Familial Hypercholesterolaemia: New Insights and Guidance for Clinicians to Improve Detection and Clinical Management. A Position Paper from the Consensus Panel on Familial Hypercholesterolaemia of the European Atherosclerosis Society. European Heart Journal, 35, 2146-2157. https://doi.org/10.1093/eurheartj/ehu274

[5] Hovingh, G.K., Davidson, M.H., Kastelein, J.J., et al. (2013) Diagnosis and Treatment of Familial Hypercholesterolaemia. European Heart Journal, 34, 962-971. https://doi.org/10.1093/eurheartj/eht015

[6] Rodriguez, F. and Knowles, J.W. (2015) PCSK9 Inhibition: Current Concepts and Lessons from Human Genetics. Current Atherosclerosis Reports, 17, 487. https://doi.org/10.1007/s11883-015-0487-8

[7] Shi, X.J., Li, M.N., Xuan, L., et al. (2019) Clinical Characteristics of Patients with Premature Acute Coronary Syndrome and Adverse Cardiovascular Events after PCI. Experimental and Therapeutic Medicine, 18, 793-801. https://doi.org/10.3892/etm.2019.7618

[8] Sadeghi, R., Adnani, N., Erfanifar, A., et al. (2013) Premature Coronary Heart Disease and Traditional Risk Factors-Can We Do Better? International Cardiovascular Research Journal, 7, 46-50.

[9] Mirza, A.J., Taha, A.Y. and Khdhir, B.R. (2018) Risk Factors for Acute Coronary Syndrome in Patients below the Age of 40 Years. The Egyptian Heart Journal, 70, 233-235. https://doi.org/10.1016/j.ehj.2018.05.005

[10] Iyengar, S.S., Gupta, R., Ravi, S., et al. (2017) Premature Coronary Artery Disease in India: Coronary Artery Disease in the Young (CADY) Registry. Indian Heart Journal, 69, 211-216. https://doi.org/10.1016/j.ihj.2016.09.009

[11] Harada-Shiba, M., Ako, J., Arai, H., et al. (2018) Prevalence of Familial Hypercholesterolemia in Patients with Acute Coronary Syndrome in Japan: Results of the EXPLORE-J Study. Atherosclerosis, 277, 362-368.

https://doi.org/10.1016/j.atherosclerosis.2018.06.856

[12] Katsiki, N., Banach, M. and Mikhailidis, D.P. (2019) Is Type 2 Diabetes Mellitus a Coronary Heart Disease Equivalent or Not? Do Not Just Enjoy the Debate and Forget the Patient! Archives of Medical Science, 15, 1357-1364. https://doi.org/10.5114/aoms.2019.89449

[13] Martín-Timón, I., Sevillano-Collantes, C., Segura-Galindo, A., et al. (2014) Type 2 Diabetes and Cardiovascular Disease: Have All Risk Factors the Same Strength? World Journal of Diabetes, 5, 444-470. https://doi.org/10.4239/wjd.v5.i4.444

[14] Aggarwal, A., Srivastava, S. and Velmurugan, M. (2016) Newer Perspectives of Coronary Artery Disease in Young. World Journal of Cardiology, 8, 728-734. https://doi.org/10.4330/wjc.v8.i12.728

[15] Harada-Shiba, M., Arai, H., Okamura, T., et al. (2012) Multicenter Study to Determine the Diagnosis Criteria of Heterozygous Familial Hypercholesterolemia in Japan. Journal of Atherosclerosis and Thrombosis, 19, 1019-1026. https://doi.org/10.5551/jat.14159

[16] Ralapanawa, U., Kumarasiri, P.V.R., Jayawickreme, K.P., et al. (2019) Epidemiology and Risk Factors of Patients with Types of Acute Coronary Syndrome Presenting to a Tertiary Care Hospital in Sri Lanka. BMC Cardiovascular Disorders, 19, 229. https://doi.org/10.1186/s12872-019-1217-x

[17] Lamelas, P., Schwalm, J.D., Quazi, I., et al. (2017) Effect of Body Mass Index on Clinical Events after Acute Coronary Syndromes. American Journal of Cardiology, 
120, 1453-1459. https://doi.org/10.1016/j.amjcard.2017.07.043

[18] Ge, J., Li, J., Yu, H., et al. (2018) Hypertension Is an Independent Predictor of Multivessel Coronary Artery Disease in Young Adults with Acute Coronary Syndrome. International Journal of Hypertension, 2018, Article ID: 7623639. https://doi.org/10.1155/2018/7623639

[19] Roy, A.K., Das, S., Chowdhury, J., et al. (2014) Tendinous Xanthoma with Familial Hypercholesterolemia. Indian Dermatology Online Journal, 5, S59-S60. https://doi.org/10.4103/2229-5178.144546

[20] Munjal, A. and Kaufman, E.J. (2020) Arcus Senilis. StatPearls Publishing, Treasure Island.

[21] Sawhney, J.P.S., Prasad, S.R., Sharma, M., et al. (2019) Prevalence of Familial Hypercholesterolemia in Premature Coronary Artery Disease Patients Admitted to a Tertiary Care Hospital in North India. Indian Heart Journal, 71, 118-122. https://doi.org/10.1016/j.ihj.2018.12.004

[22] Cordero, A., Bertomeu-González, V., Moreno-Arribas, J., et al. (2018) Prognosis and Lipid Profile Improvement by a Specialized Outpatient Clinic for Acute Coronary Syndrome Patients. Atherosclerosis, 275, 28-34. https://doi.org/10.1016/j.atherosclerosis.2018.05.026

[23] Auckle, R., Su, B., Li, H., et al. (2017) Familial Hypercholesterolemia in Chinese Patients with Premature ST-Segment-Elevation Myocardial Infarction: Prevalence, Lipid Management and 1-Year Follow-Up. PLOS ONE, 12, e0186815. https://doi.org/10.1371/journal.pone.0186815

[24] Farnier, M., Salignon-Vernay, C., Yao, H., et al. (2019) Prevalence, Risk Factor Burden, and Severity of Coronary Artery Disease in Patients with Heterozygous Familial Hypercholesterolemia Hospitalized for an Acute Myocardial Infarction: Data from the French RICO Survey. Journal of Clinical Lipidology, 13, 601-607. https://doi.org/10.1016/j.jacl.2019.06.005

[25] De Backer, G., Besseling, J., Chapman, J., et al. (2015) Prevalence and Management of Familial Hypercholesterolaemia in Coronary Patients: An Analysis of Euroaspire IV, a Study of the European Society of Cardiology. Atherosclerosis, 241, 169-175. https://doi.org/10.1016/j.atherosclerosis.2015.04.809

[26] Emanuelsson, F., Nordestgaard, B.G. and Benn, M. (2018) Familial Hypercholesterolemia and Risk of Peripheral Arterial Disease and Chronic Kidney Disease. The Journal of Clinical Endocrinology \& Metabolism, 103, 4491-4500. https://doi.org/10.1210/jc.2018-01058 